\title{
EIN ZIGEUNERISCHES LEHNWORT IM BASKISCHEN
}

In allen europäischen Zigeunerdialekten gibt es ein Wort für 'Wagen', dessen zahlreiche Varianten sich wohl auf nicht mehr als folgende drei Grundformen zurückführen lassen: 1

(1) *wordin oder *wurdin in vordin (deutsch), vordẹn (dtsch.), wortin (dtsch.), wohrtin (dtsch.), vortin (tschech.-dtsch.), wurdin (dtsch.), vurdin (dtsch.), vurdi (dtsch. dän.), wurtin (dtsch.), vårdi (schwed., norweg.), vudding (schwed.), vårdin(e) (norweg.), vårdyne (norweg.), vårdina (norweg.), vårding (schwed.), vordia (finn.).

(2) *wurdon oder *wurdun $\left({ }^{*}\right.$ wurdum $)$ in wórdum (dtsch.), wurdum (dtsch.), wurtom (dtsch.), wurtum (dtsch.), vurdon (dän., rumän.), vurdon (finn.), vurdo (schwed.), urdon (dtsch., rumän., ungar.), vordon (serb., balkan.), 'ordon (balkan.), vardo (engl.,), wardo (engl.), wohl auch vîrdon (rumän.), vrdón (serb.), vrdo (tschech.).

(3) *werdan oder *werdon in wérda(n) (dtsch.), verdan (poln.), verda (slowak., tschech.), verdo (dtsch., slowak.).

Es lohnt sich nicht, alle kleinen Abweichungen einzeln zu erörtern, zumal sie weitgehend auf Verhörungen der sprachwissenschaftlich meist nicht vorgebildeten Aufzeichner beruhen können. Erwähnt sei aber, daß $t$ in dtsch. wortin u.a. sicherlich für eine stimmlose Lenis steht, daß Stämme auf $n$ im Auslaut häufig mit solchen ohne $n$ wechseln, und daß das $m$ in wurdum durch Labialisierung aus $n$ entstanden sein kann.

Schon Miklosich hat erkannt, daß das Wort aus dem Iranischen entlehnt ist. ${ }^{2}$ Seinen Hinweis auf das etwas entlegene ossetische värdon, uordone, ordon können wir heute ergänzen durch mittelpers. (soghd.) wrtn für wartan, neupers. gärdün ${ }^{3}$ 'Wagen' < *wartōn, vgl. auch neupers. gärdän 'Hals' (als der 'sich Drehende'), wakhi wïrdän ${ }^{4}$ 'Mühlrad', alles Ableitungen von der indo-iran. Wurzel wart- 'sich drehen', die auch sonst im Neuiranischen reichlich vertreten ist. Den Zigeunerwörtern liegen zwei, wenn nicht gar drei iranische Varianten zugrunde: *wordin/*wurdin und

1 Nach Siegmund A. Wolf, Großes Wb. der Zigeunersprache (1960) Nr. 3741.

2 Über die Wanderungen und Mundarten der Zigeurner Europa's (1872-81) VIII, 96.

3 Paul Horn, Grundriß der Neupersischen Etymologie (1893) Nr. 904, dazu Hübschmann, Persische Studien (1895), der das osset. Wort mit Miller-Stachelberg, fünf osset. Erzählungen p. 69, als Entlehnung aus dem Mittelpers. auffasst.

4 G. Morgenstierne, Indo-Iranian frontier Languages, Vol. II (1938), p. 549. 
*werdan weisen auf Bildung mit -an (wie im Sogd.), *wurdon und *werdon auf Bildung mit -ōn (wie im Neupers.). Fraglich ist dagegen, ob man für zig. *wurdin und *wurdon iranische Vorformen mit der Schwundstufe *wrt- (wie in $g u l$ 'Rose' $<{ }^{*}$ wurd $<*$ wrd) oder innerzigeunerische Labialisierung $* w e->{ }^{*} w u / *$ wo annehmen soll; umgekehrt scheint auch die Tatsache, daß die $e$-Formen vor allem im slawischen Sprachgebiet vorkommen, sekundären Ursprung des $e$ nicht ganz auszuschließen.

Die Variante ${ }^{*}$ wurdin hat nun eine ziemlich genaue Entsprechung in span.-bask. burdi/gurdi 'Wagen'. Das Bask. hat kein $w$, mußte daher im Anlaut ein $b$ substituieren; $g u$-, das auch sonst im Bask. sehr häufig mit $b u$ - wechselt, zeigt denselben, wahrscheinlich als Dissimilation zu erklärenden Wandel wie das Pahlavi und Neupers. Für den Schwund des $n$ noch den innerbask. Lautvorgang wie in are $(a)$ 'Sand' $<$ lat. arena usw. $^{5}$ verantwortlich zu machen, ist vielleicht zu gewagt; eher wird man an eine zigeunerische Variante *vurdi denken, wie sie in der eingangs angeführten Liste ja auch mehrmals vorkommt.

$\mathrm{Daß}$ die spanischen Basken von den Zigeunern ein Wort für 'Wagen' übernommen haben sollen, mag zunächst überraschen, erklärt sich aber wahrscheinlich daraus, daß der ältere baskische, bis heute noch gebrauchte Wagentyp speichenlose, aus Brettern zusammengefügte Räder hatte und daher wohl primitiver war als der von den Zigeunern benützte Wohnwagen. L. Michelena hält brieflich franz.-bask. orga 'Wagen' für das echt-bask. Wort und wertet es als zusätzlichen Beweis für die fremde Herkunft von burdi/gurdi.

HEIDELBERG

5 L. Michelena, Fonética Histórica Vasca (1961) p. $300 \mathrm{ff}$. 